\title{
Genetic analysis of the connexin-26 M34T variant: identification of genotype M34T/M34T segregating with mild-moderate non-syndromic sensorineural hearing loss
}

Molecular Medicine Unit, St James's University Hospital, Leeds LS9 7TF, UK M J Houseman

Yorkshire Regional DNA Laboratory, St James's University Hospital, Leeds LS9 7TF, UK

L A Ellis

G R Taylor

Clinical and Molecular Genetics Unit, Institute of Child

Health, 30 Guilford

Street, London

WC1N 1EH and Great

Ormond Street

Hospital for Children

NHS Trust, London

WC1N 3JH, UK

A Pagnamenta

S Rickard

M Bitner-Glindzicz

Centre for Cutaneous Research, St Bartholomews' and the

Royal London School of Medicine and Dentistry, Queen

Mary, University of

London, 2 Newark

Street, Whitechapel,

London E1 2AT, UK

W-L Di

D P Kelsell

The Murdoch

Institute, Royal

Children's Hospital,

Parkville 3052,

Melbourne, Victoria,

Australia

A H Osborn

H-H M Dahl

National Centre for

Medical Genetics, Our

Lady's Hospital for

Sick Children,

Crumlin, Dublin 12, Ireland

W Reardon

Department of Clinical Genetics, St James's University Hospital, Leeds LS9 7TF, UK

R F Mueller

Correspondence to: Dr Kelsell,

kelsell@icrf.icnet.uk

Revised version received 3 November 2000

Accepted for publication

8 November 2000

Mark J Houseman, Lucy A Ellis, Alistair Pagnamenta, Wei-Li Di, Sarah Rickard, Amelia H Osborn, Hans-Henrik M Dahl, Graham R Taylor, Maria Bitner-Glindzicz, William Reardon, Robert F Mueller, David P Kelsell

\begin{abstract}
Mutations in the human gap junction $\beta-2$ gene (GJB2) that encodes connexin-26 have been shown to cause non-syndromic sensorineural hearing loss (NSSNHL) at the DFNB1 locus on 13q11. Functional and genetic data regarding the disease causing potential of one particular $G J B 2$ sequence variant, $101 \mathrm{~T} \rightarrow \mathrm{C}(\mathrm{M} 34 \mathrm{~T})$, have proven contradictory. In this study, we found the prevalence of the M34T allele in a cohort of white sib pairs and sporadic cases with NSSNHL from the United Kingdom and Ireland to be $3.179 \%$ of chromosomes screened. Significantly, we identified the first M34T/M34T genotype cosegregating in a single family with mid to high frequency NSSNHL. Screening a control population of 630 subjects we identified 25 M34T heterozygotes; however, no M34T homozygotes were detected. Surprisingly, the majority of M34T alleles (88\%) were in cis with a 10 bp deletion in the $5^{\prime}$ non-coding sequence. This non-coding deletion was also homozygous in the homozygous M34T subjects. Microsatellite analysis of flanking loci in M34T heterozygotes and controls does not define an extensive ancestral haplotype but preliminary data suggest two common alleles in subjects with the M34T allele. In summary, we provide data that support M34T acting as a recessive GJB2 allele associated with mild-moderate prelingual hearing impairment.

(F Med Genet 2001;38:20-25)
\end{abstract}

Keywords: GfB2; connexin-26; M34T; hearing loss

The gap junction $\beta-2$ gene (GFB2, MIM $121011)$, encoding connexin-26 (Cx26), is a member of the highly conserved connexin multigene family which encode integral membrane proteins that represent the structural component of gap junction intercellular channels. ${ }^{1}$ In 1997, mutations in GFB2 were shown to be responsible for non-syndromic autosomal recessive hearing loss at the $D F N B 1$ locus. $^{23}$ Subsequent analysis of $G \mathcal{F B} 2$ has led to identification of over 50 coding mutations (The Connexin-Deafness Homepage: http:// www.iro.es/CX26deaf.html). One particular mutation, $35 \mathrm{delG}$, accounts for up to $50 \%$ of autosomal recessive non-syndromic sen- sorineural hearing loss (NSSNHL) in some white populations. ${ }^{4}$ The frequency of the 35 delG mutant allele varies in different populations, but may be as prevalent as $4 \%$ in particular ethnic groups. ${ }^{5}$ Two other common Cx26 mutations are $167 \mathrm{delT}$ and $235 \mathrm{delC}$ in cohorts of Ashkenazi Jews (4\%) and Japanese $(1 \%)$, respectively. ${ }^{6}$

The causal association of $C \times 26$ sequence variants detected in subjects with NSSNHL and the disease phenotype is based upon a number of standard criteria that include the segregation of the variant in affected subjects, its absence in controls, predicted effect on protein function, and data derived from functional analyses. However, the significance of one particular sequence variant of $C x 26,101 \mathrm{~T} \rightarrow \mathrm{C}$ (M34T), has proven difficult to assess given apparent contradictory genetic and functional observations.

The M34T amino acid substitution was first proposed as a dominant mutation (a candidate for the DFNA3 locus) from the analysis of a single family in which palmoplantar keratoderma and various forms of deafness were segregating. ${ }^{2}$ In this small family, two sisters with profound sensorineural hearing loss were heterozygous for the M34T allele. Subsequent analysis of family members showed the association of M34T with profound hearing loss only when M34T was in trans with a dominant GFB2 mutation, D66H. ${ }^{8}$ Functional data generated using the Xenopus laevis paired oocyte assay showed that M34T Cx26 protein was a dominant disrupter of normal channel formation. ${ }^{9}$ Further support for its deleterious nature was shown using the mammalian $\mathrm{HeLa}$ cell expression assay. This showed that M34T $\mathrm{Cx} 26$ protein was targeted to the plasma membrane, but there was a significant reduction in oligomerisation and intercellular coupling owing to a net decrease in the amount of M34T containing connexons in the plasma membrane. ${ }^{10}$ Contradictory to these functional observations, the reports of the M34T allele in normal hearing subjects suggests the sequence variant does not function as a dominant, pathogenic variant in vivo (table 1 ). Thus, the M34T allele does not segregate with dominant hearing loss. Instead, the association of M34T in trans with alleles V95M, R184W, and 35 delG in subjects with NSSNHL suggests a recessive mode of action. ${ }^{11} 12$ 
Table 1 A summary of GFB2 studies assessing the prevalence of the M34T allele

\begin{tabular}{|c|c|c|c|c|c|c|}
\hline \multirow{2}{*}{$\begin{array}{l}\text { Population } \\
\text { ethnicity }\end{array}$} & \multicolumn{2}{|c|}{$\begin{array}{l}\text { Cohort with NSSNHL } \\
\text { chromosomes screened }\end{array}$} & \multirow{2}{*}{$\begin{array}{l}\text { M34T } \\
\text { frequency (\%) }\end{array}$} & \multirow{2}{*}{$\begin{array}{l}\text { Control } \\
\text { chromosomes } \\
\text { screened }\end{array}$} & \multirow{2}{*}{$\begin{array}{l}\text { M34T } \\
\text { frequency (\%) }\end{array}$} & \multirow[b]{2}{*}{ Refs } \\
\hline & Sib pair & Sporadic & & & & \\
\hline Spanish/Italian & 620 & 874 & 0.067 & - & - & $3,4,19$ \\
\hline Japanese & 98 & 50 & 0.000 & 518 & 0.000 & $7,20,21$ \\
\hline French & 94 & 114 & 0.000 & - & - & 22 \\
\hline American & 130 & - & 1.538 & 392 & 0.765 & 11,23 \\
\hline Israeli & 150 & - & 0.000 & - & - & 15 \\
\hline Mixed & 148 & - & 3.378 & - & - & 12 \\
\hline British/Irish & 214 & 132 & 3.179 & 1260 & 1.984 & This study \\
\hline
\end{tabular}

Recently, a family consistent with recessive inheritance for NSSNHL has been described in which the M34T allele is segregating with a common GFB2 recessive allele, $167 \mathrm{delT} .^{13}$ In this family, one subject was a $167 \mathrm{delT} / \mathrm{M} 34 \mathrm{~T}$ compound heterozygote. The audiometric pattern in this person was said to be compatible with high frequency hearing loss.

In this study, we have screened affected sib pairs and sporadic cases from the UK and Irish population with moderate to profound prelingual NSSNHL for the M34T allele. In addition, a group of 630 controls (hearing status unknown) from the UK was also analysed. These analyses were performed in order to ascertain the phenotype of M34T/M34T homozygotes and also to assess the frequency of this variant in the British/Irish population.

\section{Materials and methods}

CRITERIA FOR INCLUSION IN THE STUDY

A cohort of $107 \mathrm{sib}$ pairs and 66 sporadic cases with NSSNHL was collected from the British and Irish population. In all cases, clinical examinations were normal, thus excluding syndromal deafness, as were routine histories for acquired hearing loss caused by infection or ototoxic drugs. Ten $\mathrm{ml}$ of venous blood was collected from each patient and DNA extracted from peripheral blood lymphocytes using a standard non-organic extraction procedure. DNA was also analysed from 630 anonymised subjects resident in the UK (hearing status unknown) which formed our control population.

POLYMERASE CHAIN REACTION (PCR) AND SEQUENCING

PCR was performed in a $30 \mu \mathrm{l}$ volume comprising $40 \mathrm{ng}$ genomic DNA, $10 \mathrm{pmol}$ of sense and antisense primer, $10 \mathrm{mmol} / 1$ Tris-

Table 2 Oligonucleotide primers used in GfB2 analysis. Primer pair M34T-F/R was used to screen for the M34T coding variant. Primer pairs Cx26-9F/R, Cx26-10F/R, Cx14-F/R, $C \times 26-16 F / R$, and $C \times 26-18 F / R$ were used to amplify non-coding sequences and non-coding exon 1 (Genbank AF144321)

\begin{tabular}{|c|c|c|c|}
\hline Primer & Sequence & $\begin{array}{l}\text { Annealing } \\
\text { temp }\left({ }^{\circ} \mathrm{C}\right)\end{array}$ & $\begin{array}{l}\text { Enzyme used for } \\
\text { SSCP }\end{array}$ \\
\hline $\begin{array}{l}\text { M34T-F } \\
\text { M34T-R }\end{array}$ & $\begin{array}{l}\text { d-CCGTCCTCTTCATTTTTCGCATCA } \\
\text { d-CACGTGCATGGCCACTAG }\end{array}$ & 63 & N/A \\
\hline $\mathrm{C} \times 26-9 \mathrm{~F}$ & d-CTGCAGAAACTGCCTAGGTC & 58 & HinfI \\
\hline $\mathrm{C} \times 26-9 \mathrm{R}$ & d-CTTTGTCTCAGATTATGAGG & & \\
\hline $\mathrm{Cx} 26-10 \mathrm{~F}$ & d-CATCTTAGTCCCTCATCCGC & 58 & $\operatorname{Hinf\mathrm {I}}$ \\
\hline $\mathrm{Cx} 26-10 \mathrm{R}$ & d-TCCGAACGAACGCCTTCTCG & & \\
\hline $\mathrm{Cx} 26-14 \mathrm{~F}$ & d-CCCCAACCTTAGTCCTTGGC & 58 & $B g l \mathrm{II}$ \\
\hline $\mathrm{Cx} 26-14 \mathrm{R}$ & d-GCGCTGTGCCGTGGGCGGG & & \\
\hline $\mathrm{Cx} 26-16 \mathrm{~F}$ & d-ATGCGGACTACAGAGGAGA & 55 & EarI \\
\hline $\mathrm{Cx} 26-16 \mathrm{R}$ & d-TCCGAGTCGGGGAGAGGAG & & \\
\hline $\mathrm{Cx} 26-18 \mathrm{~F}$ & d-TGCGGTTAAAAGGCGCCAC & 55 & StyI \\
\hline $\mathrm{Cx} 26-18 \mathrm{R}$ & d-ATTCCAGCTCCGGAGCTCGG & & \\
\hline
\end{tabular}

$\mathrm{HCl}(\mathrm{pH} 8.3), 50 \mathrm{mmol} / 1 \mathrm{KCl}, 1.5 \mathrm{mmol} / \mathrm{l}$ $\mathrm{MgCl}_{2}, 0.1 \%$ (v/v) TritonX-100, a $200 \mu \mathrm{mol} / 1$ concentration of each dNTP, and 1 unit of Taq DNA polymerase (Gibco BRL). Amplification conditions were as follows: $94^{\circ} \mathrm{C}$ for five minutes, 33 cycles of $94^{\circ} \mathrm{C}$ for 30 seconds, annealing temperature (table 2 ) for 30 seconds, and $72^{\circ} \mathrm{C}$ for 30 seconds, followed by $72^{\circ} \mathrm{C}$ for five minutes. PCR products were separated on a $1 \%(\mathrm{w} / \mathrm{v})$ agarose gel and bands of expected size were excised and purified using the QIAquick Gel Extraction Kit (Qiagen). For sequencing, approximately 300 ng PCR product was used as template with the BigDye Terminator Cycle Sequencing Reaction Kit (PE Applied Biosystems). The products were visualised on an ABI377 DNA sequencer (PE Applied Biosystems).

M34T IDENTIFICATION AND CODING SEQUENCE ANALYSIS

Primers M34T F/R were designed to amplify a 209 bp fragment of GFB2 (table 2). PCR was performed in a $15 \mu \mathrm{l}$ reaction volume with the following conditions: $94^{\circ} \mathrm{C}$ for two minutes, 30 cycles of $63^{\circ} \mathrm{C}$ for one minute, followed by $72^{\circ} \mathrm{C}$ for two minutes. An $8 \mu \mathrm{l}$ aliquot of PCR product was used in a $15 \mu \mathrm{l}$ restriction digest reaction with $H s p 9211$ according to instruction (Promega). The digest products were resolved on a 3\% Metaphor gel (FMC Bioproducts) and compared to wild type (189 bp only) and heterozygous M34T (189 bp and 209 bp) controls. Confirmation of M34T genotypes and identification of compound mutations was performed by sequencing the entire $C \times 26$ coding region as described previously. ${ }^{2}$

CLONING OF G尹B2 PCR FRAGMENTS

PCR products were cloned using the pGEM ${ }^{\circledR}-T$ Easy Vector System (Promega). PCR products were ligated overnight at $14^{\circ} \mathrm{C}$ and transformed into competent INValphaF' $E$ coli (Invitrogen). Transformed cells were plated onto Luria-Bertani (LB)/ampicillin plates and incubated overnight at $37^{\circ} \mathrm{C}$. Ten colonies were picked into $100 \mu \mathrm{LB}$ and incubated for one hour at $37^{\circ} \mathrm{C}$. The LB broth was centrifuged, the pellet resuspended in $20 \mu \mathrm{l}$ of TE ( $\mathrm{pH} \mathrm{8.0)}$, and heated at $75^{\circ} \mathrm{C}$ for five minutes. A $2 \mu \mathrm{l}$ aliquot was used in PCR reactions as described previously and the PCR product sequenced.

SCREENING NON-CODING SEQUENCES BY SSCP The non-coding sequence of $G \mathcal{F B} 2$ was amplified using the primer pairs listed in table 2. Two $\mu l$ of PCR product was restriction enzyme digested in a total volume of $20 \mu \mathrm{l}$ according to the manufacturer's instruction (table 2, Promega and New England Biolabs) and $3 \mu \mathrm{l}$ of the digest reaction was mixed with $3 \mu \mathrm{l}$ of $95 \%(\mathrm{v} / \mathrm{v})$ formamide, $20 \mathrm{mmol} / 1 \mathrm{EDTA}$, $0.05 \%(\mathrm{w} / \mathrm{v})$ bromophenol blue, and $0.05 \%$ $(\mathrm{w} / \mathrm{v})$ xylene cyanol. The sample was heated at $95^{\circ} \mathrm{C}$ for five minutes, cooled on ice for five minutes, and loaded onto a $12.5 \%(\mathrm{w} / \mathrm{v})$ nondenaturing polyacrylamide gel (GenGel Excel 12.5, Pharmacia Biotech). Electrophoresis was performed at $25 \mathrm{~mA} / 14^{\circ} \mathrm{C}$ for 90 minutes (Genephor Unit, Pharmacia Biotech) and the 
Table 3 A summary of the sib pair (SP) and sporadic (S) cases with NSSNHL identified with M34T or -493 del10 sequence variants. A or B after the SP prefix denotes sib 1 or 2; in some cases only one sib was available for screening

\begin{tabular}{lll}
\hline Family & GFB2 coding status & Non-coding status \\
\hline SP1A & M34T/M34T & -493del10/-493del10 \\
SP1B & M34T/M34T & -493del10/-493del10 \\
SP2A & M34T/wild type & -493del10/wild type \\
SP2B & M34T/wild type & -493del10/wild type \\
SP3A & M34T/wild type & -493del10/wild type \\
SP3B & Wild type/wild type & Wild type/wild type \\
SP4A & M34T/wild type & -493del10/wild type \\
SP4B & Wild type/wild type & Wild type/wild type \\
SP5A & M34T/35delG & -493del10/wild type \\
SP5B & 35delG/wild type & Wild type/wild type \\
SP6A & M34T/35delG & Wild type/wild type \\
SP7A & M34T/wild type & -493del10/wild type \\
S1 & M34T/wild type & -493del10/wild type \\
S2 & M34T/wild type & -493del10/wild type \\
S3 & M34T/wild type & -493del10/wild type \\
\hline
\end{tabular}

DNA visualised following silver staining. Samples with a different electrophoretic mobility to known wild type controls were sequenced.

IDENTIFICATION OF THE - 493DEL10 VARIANT For each subject, the Cx26-14 fragment (383 bp) was PCR amplified and an $8 \mu \mathrm{l}$ aliquot transferred to a $20 \mu \mathrm{l}$ digest reaction with $B g l \mathrm{II}$ restriction enzyme. Then $10 \mu \mathrm{l}$ of digest product was visualised on a $1 \%$ agarose gel following electrophoresis for 30 minutes. In the absence of -493 del10, the PCR product is cut into two fragments of $143 \mathrm{bp}$ and $240 \mathrm{bp}$.

HAPLOTYPE ANALYSIS

Genotyping markers D13S1835, D13S141, D13S175, and D13S1831 from 13q11 were used to generate haplotypes for subjects with the M34T allele and some family members. PCR product was visualised using an ABI 377 and analysed with Genotyper software according to instruction (PE Applied Biosystems).

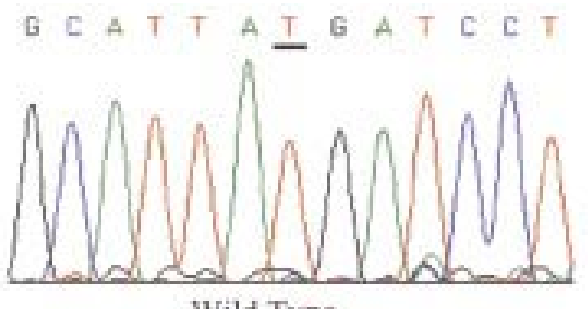

Wild Type

A

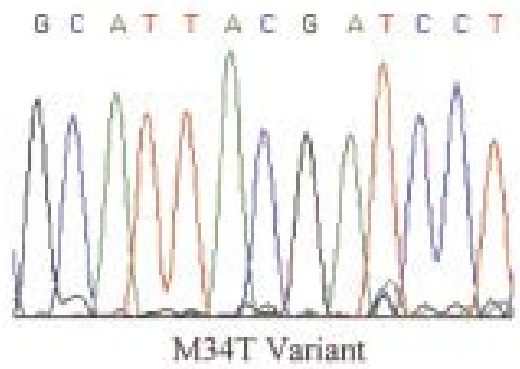

CELL CULTURE AND RT-PCR ANALYSIS OF M34T/WT CELL LINES

Towards investigating the expression of the M34T allele, we screened DNA extracted from a number of anonymised primary keratinocyte cultures and cell lines for the M34T allele. M34T heterozygotes were identified in one primary keratinocyte culture and in four cell lines. These samples were also heterozygous for -493del10. Primary keratinocytes were prepared by enzymatic dispersion and cultured. ${ }^{14}$ Cell pellets for the cell lines A431 derived from epidermoid carcinoma, $833 \mathrm{~K}$ derived from testicular tumour line, ASPC-1 derived from pancreatic adenocarcinoma, and XPG415 derived from skin fibroblasts (xeroderma pigmentosum group $\mathrm{G}$ ) were obtained from Research Cell Services at the Imperial Cancer Research Fund. Total RNA was extracted using Trizol reagent (Life Technologies, UK). RNA ( $1 \mu \mathrm{g}$ ) was reverse transcribed to first strand cDNA by moloney murine leukemia virus reverse transcriptase and random hexamer (Perkin Elmer, $\mathrm{UK}$ ) in $20 \mu \mathrm{l}$ of reaction mixture, and $5 \mu \mathrm{l}$ of RT product was applied to PCR using Taq DNA polymerase (Perkin Elmer, UK) with forward primer CAGCGCAGAGACCCCAACGC and reverse primer GACACGAAGATCAGCTGCAG (5'-3'). The PCR programme was $94^{\circ} \mathrm{C}$ for two minutes, followed by 35 cycles as follows: $94^{\circ} \mathrm{C}$ for $30 \mathrm{sec}-$ onds, $60^{\circ} \mathrm{C}$ for 30 seconds, $72^{\circ} \mathrm{C}$ for 45 seconds, and completed for a final extension of $72^{\circ} \mathrm{C}$ for 10 minutes. RT-PCR products were checked on $1 \%$ agarose gel and sequenced using BigDye Sequencing chemistry (PerkinElmer, UK).

\section{Results}

The M34T allele was detected in seven of 107 sib pairs and three of 66 sporadic cases with NSSNHL. In three of the seven sib pairs (SP3, SP4, and SP5) the M34T allele did not segre-
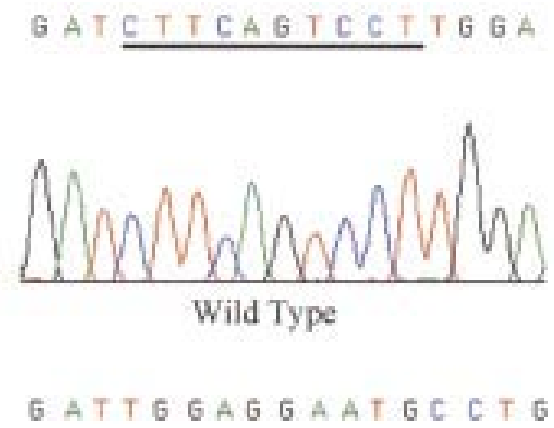

B

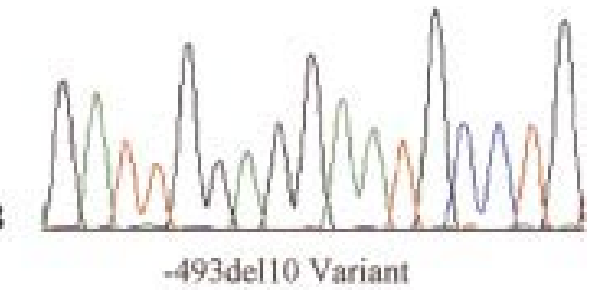

Figure 1 Sequence electrophoretograms taken from an ABI 377 representing (A) wild type and homozygous $M 34 T$ traces and (B) wild type and homozygous -493 del10 traces. The underlined nucleotide(s) in the wild type sequence denote the base(s) modified in the variant. 


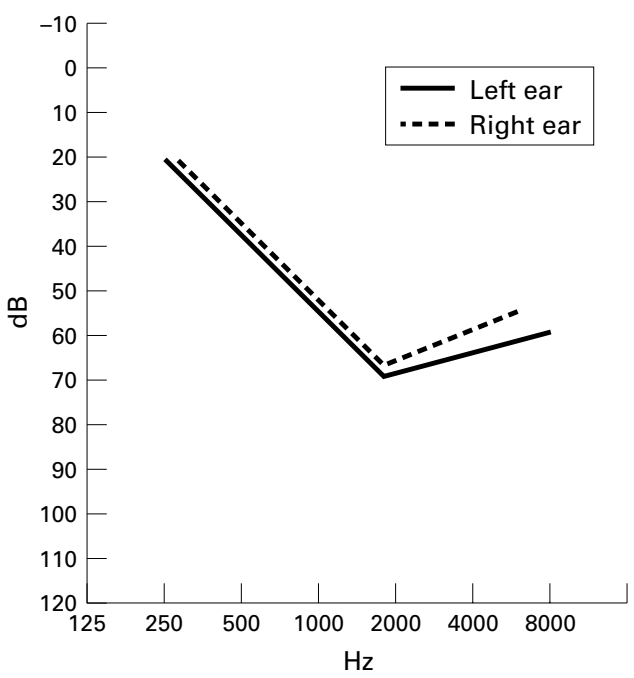

Figure 2 Tonal audiometric curves from both ears in one M34T homozygote identified in the study.

gate in both affected subjects and in two cases (SP6 and SP7) only one sib was available for testing (table 3). Significantly, we identified the first subjects homozygous (designated sib pair SP1) for the M34T sequence variant (table 3, fig 1A). The affected offspring presented with a mild-moderate prelingual bilateral hearing loss (fig 2). Their normal hearing sister was heterozygous for M34T. In addition, we screened 630 anonymous subjects (whose hearing status was not available) and did not identify any further M34T homozygotes. However, the M34T allele was detected in 25 of the 1260 (1.984\%) chromosomes screened compared to a frequency of $3.179 \%$ in the NSSNHL cohort (table 1).

Sequence analysis of the coding region in M34T sib pair and sporadic cases indicated that two sib pairs (SP5A and SP6A) were compound heterozygotes with the $35 \mathrm{delG}$ mutant GFB2 allele (table 3). The audiogram of subject SP6A showed a U shaped moderate NSSNHL. Subject SP5A has William's syndrome and is thought to have a mild-moderate sensorineural hearing loss. Subcloning the PCR fragments in these subjects established that both sequence variants were in trans. DNA from the second affected sib was available for analysis in one of the families (SP5B) and was

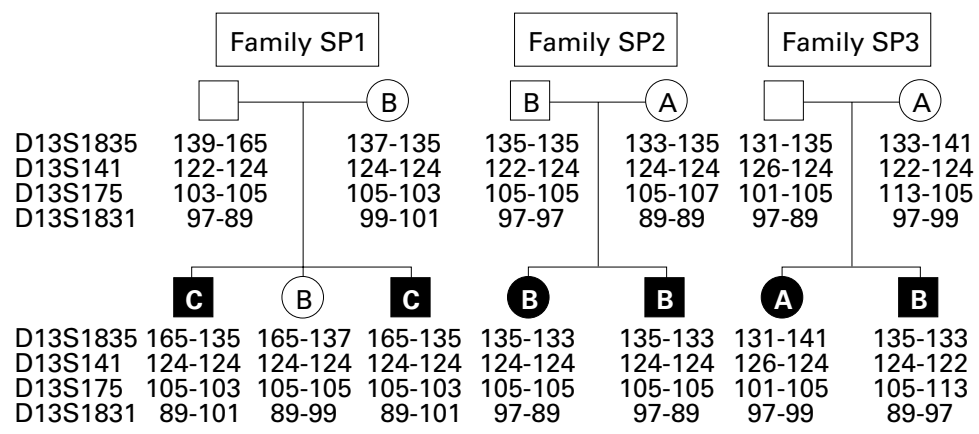

Figure 3 Haplotype analysis of M34T/10 bp deletion families. Microsatellite markers D13S1385 and D13S141 are centromeric to GFB2 and D13S175 and D13S1381 are telomeric. D13S1385, D13S141, and D13S175 flank GFB2 in an interval of $<500 \mathrm{~kb}$, and D13S1381 maps more telomeric. ${ }^{24}{ }^{25}$ Allele sizes are shown in bp. The letter assigned to a subject in the pedigree denotes the M34T/-493del10 G7B2 genotype: (A) wild type, (B) heterozygous M34T/-493del10, and (C) homozygous M34T/-493del10. shown to carry only the $35 \mathrm{delG}$ mutation. This subject had profound NSSNHL. Thus, M34T did not segregate with NSSNHL in this family. No other GFB2 mutations were detected in the NSSNHL M34T heterozygotes.

To extend the analysis of the genetic background of M34T gene heterozygotes with NSSNHL in which no second GFB2 coding mutation was detected, we performed SSCP analysis of the non-coding exon 1 and $1.5 \mathrm{~kb}$ of sequence immediately 5 ' to exon 1 . In the seven M34T heterozygotes analysed, a heterozygous $10 \mathrm{bp}$ deletion was identified in the non-coding upstream sequence (fragment $C \times 26-14$ ), spanning nucleotides -493 to -502 , relative to the transcription start site of exon 1 (-493del10). The -493 del10 variant was subsequently detected on the basis that it abolishes a BglII restriction enzyme site. Extending this analysis to the remaining subjects with M34T (SP1, SP5, and SP6A) identified that two of the three also carried -493 del10. The -493 del10 variant was in a homozygous state in both M34T homozygous offspring (fig $1 \mathrm{~B}$ ). To assess the prevalence of -493 del10 in other subjects with NSSNHL, we screened the remaining $100 \mathrm{sib}$ pairs and 63 sporadic cases. In three of 100 $(3.0 \%)$ sib pairs and two of $63(3.2 \%)$ sporadic cases, the -493 del10 variant was identified. Three of the four analysed M34T heterozygotes with mild-moderate NSSNHL from Australia were also heterozygous for -493 del10. Two of them were compound heterozygotes with $35 \mathrm{delG}$. In the control population, 22 of the $25(88.0 \%)$ M34T heterozygotes and 40 subjects $(6.4 \%)$ without the M34T allele also carried -493del10. No additional -493 del10 homozygotes were detected in the remaining subjects with NSSNHL or from the control population.

Our data suggest that there is linkage disequilibrium between M34T and -493 del10. On this premise, we hypothesised that M34T is an ancestral mutation occurring on a GfB2 allele previously harbouring -493 del10. To identify this proposed ancestral haplotype, four microsatellite markers spanning a $<1 \mathrm{cM}$ interval encompassing the GFB2 locus were used to genotype M34T heterozygotes and some family members (fig 3 ). In the homozygous M34T subjects, homozygosity was only observed with marker D13S141 (allele size $124 \mathrm{bp}$ ). Analysis of three other sib pair families identified a common M34T/ -493 del10 deletion haplotype at the loci D13S1835, D13S141, and D13S175 (allele sizes $135 \mathrm{bp}, 124 \mathrm{bp}$, and $105 \mathrm{bp}$ respectively). The frequency of this proposed haplotype was assessed in M34T/-493del10 deletion heterozygotes and then compared with a control group previously shown not to have M34T or -493 del10 alleles. In 14 of 23 (60.9\%) heterozygotes the proposed haplotype was possible; however, without other family members available for testing it is difficult to determine which alleles cosegregate with the M34T/-493del10 allele. Refining the haplotype to flanking markers D13S141 (124 bp) and D13S175 (105 bp) increases the number of $\mathrm{M} 34 \mathrm{~T} /-493$ del10 heterozygotes to 20 of $23(87.0 \%)$. Analysis of 
the control group indicates that six of 32 $(18.8 \%)$ subjects have the extended haplotype, increasing to 11 of $32(34.4 \%)$ with the refined haplotype.

In addition, we investigated whether -493 del10 had an effect on the transcription of Cx26, specifically that of M34T. RT-PCR was performed on cultured keratinocytes from a heterozygote for the $\mathrm{M} 34 \mathrm{~T} /-493$ del10 allele. In addition, four cell lines with the same genotype were also analysed. Direct sequencing of the resulting $C x 26$ PCR products showed that the $\mathrm{M} 34 \mathrm{~T} /-493$ del10 allele was expressed (data not shown).

\section{Discussion}

Investigation of the M34T mutant allele in sib pairs $(6.5 \%)$ and sporadic cases $(4.5 \%)$ with NSSNHL from the UK and Ireland has led to identification of the first M34T homozygote. Both sibs presented with mid to high frequency prelingual hearing loss supporting previous reports of $\mathrm{M} 34 \mathrm{~T}$ acting as a recessive $G \mathcal{F B} 2$ hearing loss allele. Compound heterozygotes of M34T with 35delG were also identified; however, segregation analyses showed that M34T did not segregate with NSSNHL in one family. This observation could be explained by hearing loss being the result of a mutation in another hearing loss associated gene.

Genetic studies of GFB2 suggest that the M34T variant is more prevalent in the mid-west American ( 1 in 130 chromosomes), UK, and Irish (1 in 50.4 chromosomes) normal hearing populations (table 1), but has reduced frequency or absence in those of French, Spanish, Italian, and Japanese ethnic origin. These population data suggest that a single ancestral mutation event occurring originally in the UK or Ireland may account for these population differences in numbers of M34T heterozygotes. Indeed, the occurrence of the -493 del1 0 variant in cis with M34T may represent a marker of this proposed founding allele. Microsatellite analysis using four markers, three of which map to within $<500 \mathrm{~kb}$ of GFB2, showed an association of M34T with D13S141 (allele size $124 \mathrm{bp}$ ) and D13S175 (allele size $105 \mathrm{bp}$ ). The markers D13S141 and D13S175 flank GfB2 and have been used previously to identify a common haplotype for the 167 delT mutation. ${ }^{615}$ However, the homozygous M34T subjects identified in this study were only homozygous for the $124 \mathrm{bp}$ allele at the D13S141 locus in addition to -493 del10. The possibility of historical recombination events and/or microsatellite mutations masking a common haplotype may explain these observations. Extended analysis of M34T subjects with closer microsatellite markers or SNPs may show more conclusive evidence for a founding haplotype.

The role of -493 del 10 in $G \mathcal{F B 2}$ regulation is difficult to define. Recently, a single nucleotide substitution identified in the regulatory region of presenilin 1 was shown to reduce reporter gene expression by $30 \%$ in transiently transfected neuroblastoma cells. ${ }^{16}$ The $G F B 2$ regulatory region has been characterised to some extent in certain human cell lines and indicates that the $128 \mathrm{bp}$ immediately upstream of exon 1 are important for gene expression. ${ }^{17}$ However, the -493 del10 variant is positioned outside this putative regulatory region $(-493$ to -502). From analysis of cultured keratinocytes and cell lines, the M34T/-493del10 allele was expressed. This result suggests two possibilities for the mode of action of -493 del10. Firstly, the deletion may only affect promoter activity in certain cell types such as the epithelial cells of the inner ear and not in the epidermis. However, the analysis used was not quantitative so subtle differences in expression would not have been identified. Alternatively, -493 del10 is a neutral polymorphism that has little or no biological consequence on $C \times 26 \mathrm{mRNA}$ and protein levels. In support of the latter is the identification of a few subjects heterozygous for M34T who did not have -493 del10 but had normal hearing and a subject (SP6A) with moderate NSSNHL who was a compound heterozygote for M34T/35delG without -493 del 10 .

A number of reports of $35 \mathrm{delG}$ (mildmoderate), 167 delT (compatible with high frequency), V95M (degree of hearing impairment not known), R184W (mild), and now M34T (mid-high frequency), associated in trans with an M34T allele supports the recessive nature of M34T. ${ }^{11-13}$ Both 35delG and $167 \mathrm{delT}$ are frameshift mutations that truncate the $\mathrm{Cx} 26$ protein at codon 13 and 81 respectively. In vitro studies of $C \times 32$ have shown that truncation of the protein before amino acid 207 has deleterious effects on targeting to the membrane, oligomerisation, and channel function. ${ }^{18}$ Therefore, in 35delG/M34T and $167 \mathrm{delT} /$ M34T subjects, the frameshift mutant allele should have no or little effect in gap junction formation and function..$^{18}$ On this premise, the M34T protein, which has been to shown to reach the membrane, ${ }^{10}$ is solely contributing to the $C \times 26$ associated gap junction channels in the cochlea. These data suggest that further research into the role of M34T and NSSNHL is required so that genetic counselling can be provided, particularly in the UK and Ireland which have a high M34T heterozygote frequency.

We would like to thank all the participants for taking part in the study. This work was supported by the NHS Research and Development Trust, Wellcome Trust, National Lotteries Charity Board through Defeating Deafness, the European Union Framework V, and a bequest from the Special Trustess of St Bartholomews' Hospital. 1 Bruzzone R, White TW, Paul DL. Connections with connexins: the molecular basis of direc

2 Kelsell DP, Dunlop J, Stevens HP, Lench NJ, Liang JN, Parry G, et al. Connexin 26 mutations in hereditary non-syndromic sensorineural deafness. Nature 1997; 387(6628):80-3

3 Zelante L, Gasparini P, Estivill X, Melchionda S, D'Agruma $\mathrm{L}$, Govea $\mathrm{N}$, et al. Connexin 26 mutations associated with the most common form of non-syndromic neurosensory autosomal recessive deafness (DFNB1) in Mediterraneans. Hum Mol Genet 1997;6:1605-9.

4 Estivill X, Fortina P, Surrey S, Rabionet R, Melchionda S, D'Agruma L, et al. Connexin-26 mutations in sporadic and
inherited sensorineural deafness. Lancet 1998;351:394-8.

5 Gasparini P, Rabionet R, Barbujani G, Melchionda S, Gasparini P, Rabionet R, Barbujani G, Melchionda $\mathrm{S}$,
Petersen M, Brondum-Nielsen K, et al. High carrier Petersen $M$, Brondum-Nielsen $\mathrm{K}$, et al. High carrier
frequency of the $35 \mathrm{del}$ deafness mutation in European frequency of the $35 \mathrm{del} G$ deafness mutation in European
populations. Genetic Analysis Consortium of GJB2 35delG. Eur f Hum Genet 2000;8: 19-23. 
6 Morell RJ, Kim HJ, Hood LJ, Goforth L, Friderici K, Fisher $\mathrm{R}$, et al. Mutations in the connexin 26 gene (GJB2) among Engl f Med 1998;339:1500-5.

7 Kudo T, Ikeda K, Kure S, Matsubara Y, Oshima T, Watanabe K, et al. Novel mutations in the connexin 26 gene (GJB2) responsible for childhood deafness in the Japanese population. Am F Med Genet 2000;90:141-5.

8 Kelsell DP, Wilgoss AL, Richard G, Stevens HP, Munro CS, Leigh IM. Connexin mutations associated with palmoplantar keratoderma and profound deafness in a single family. Eur ₹ Hum Genet 2000;8:141-4

9 White TW, Deans MR, Kelsell DP, Paul DL. Connexin mutations in deafness. Nature 1998;394:630-1.

10 Martin PE, S LC, Casalotti SO, Forge A, Evans WH. Properties of connexin26 gap junctional proteins derived from mutations associated with non-syndromal heriditary deafness. Hum Mol Genet 1999;8:2369-76.

11 Kelley PM, Harris DJ, Comer BC, Askew JW, Fowler T, Smith SD, et al. Novel mutations in the connexin 26 gene (GJB2) that cause autosomal recessive (DFNB1) hearing (GJB2) that cause autosomal recessive

12 Wilcox SA, Saunders K, Osborn AH, Arnold A, Wunderlich $\mathrm{J}$, Kelly T, et al. High frequency hearing loss correlated with mutations in the GJB2 gene. Hum Genet 2000;106(4):399405.

13 Griffith AJ, Chowdhry AA, Kurima K, Hood LJ, Keats B mal recessive nonsyndromic neurosensory deafness at DFNB1 not associated with the compound-heterozygous GJB2 (connexin 26) genotype M34T/167delT. Am 7 Hum Genet 2000;67:745-9.

14 Leigh IM, Watt FM. Keratinocyte methods. Cambridge: Cambridge University Press, 1994.

15 Sobe T, Vreugde S, Shahin H, Berlin M, Davis N, Kanaan M, et al. The prevalence and expression of inherited connexin 26 mutations associated with nonsyndromic hearing loss in the Israeli population. Hum Genet 2000;106:50-7.

16 Theuns J, Del-Favero J, Dermaut B, van Duijn CM, Backhovens H, Van den Broeck MV, et al. Genetic variability in the regulatory region of presenilin 1 associated with ity in the regulatory region of presenilin 1 associated with
risk for Alzheimer's disease and variable expression. Hum Mol Genet 2000;9:325-31.
17 Tu ZJ, Kiang DT. Mapping and characterization of the basal promoter of the human connexin 26 gene. Biochim Biophys Acta 1998;1443:169-81.

18 Martin PE, Mambetisaeva ET, Archer DA, George CH, Evans WH. Analysis of gap junction assembly using mutated connexins detected in Charcot-Marie-Tooth X-linked disease. 7 Neurochem 2000;74:711-20.

19 Rabionet R, Zelante L, Lopez-Bigas N, D'Agruma L, Melchionda S, Restagno G, et al. Molecular basis of childhood deafness resulting from mutations in the GJB2 (connexin 26) gene. Hum Genet 2000;106:40-4.

20 Abe S, Usami S, Shinkawa H, Kelley PM, Kimberling WJ. Prevalent connexin 26 gene (GJB2) mutations in Japanese. f Med Genet 2000;37:41-3.

21 Fuse Y, Doi K, Hasegawa T, Sugii A, Hibino H, Kubo T Three novel connexin26 gene mutations in autosomal recessive non-syndromic deafness. Neuroreport 1999;10: 1853-7.

22 Denoyelle F, Marlin S, Weil D, Moatti L, Chauvin P, Garabedian EN, et al. Clinical features of the prevalent form of childhood deafness, DFNB1, due to a connexin-26 gene defect: implications for genetic counselling. Lancet 1999;353:1298-303.

23 Scott DA, Kraft ML, Carmi R, Ramesh A, Elbedour K, Yairi $\mathrm{Y}$, et al. Identification of mutations in the connexin 26 gene that cause autosomal recessive nonsyndromic hearing loss. Hum Mutat 1998;11:387-94.

24 Kibar Z, Dube MP, Powell J, McCuaig C, Hayflick SJ, Zonana $\mathrm{J}$, et al. Clouston hidrotic ectodermal dysplasia (HED): genetic homogeneity, presence of a founder effect in the French Canadian population and fine genetic mapping. Eur f Hum Genet 2000;8:372-80.

25 Lamartine J, Essenfelder GM, Kibar Z, Lanneluc I, Callouet E, Laoudj D, Lemaitre G, Hand C, Haytfick SJ, Zonana J, Antonorakis S, Kelsell DP, Christianson AL, Pitaval A, Der Kaloustian V, Blanchet-Bardon C, Rouleau GA, Waksman G. Mutations in the human connexin-30 gene (GJB6) causes hidrotic ectodermal dysplasia (Clouston syndrome). Nat Genet 2000;26:142-4. 